OPEN ACCESS

Edited by:

George Grant,

University of Aberdeen,

United Kingdom

Reviewed by:

Ajay Pradhan,

Örebro University, Sweden

Maurizio Acampa,

Siena University Hospital, Italy Walter Malorni,

National Institute of Health (ISS), Italy

*Correspondence:

Susan Wray

s.wray@liv.ac.uk

Specialty section:

This article was submitted to Clinical and Translational Physiology,

a section of the journal

Frontiers in Physiology

Received: 08 November 2020

Accepted: 15 January 2021

Published: 09 February 2021

Citation:

Wray S and Arrowsmith S (2021) The Physiological Mechanisms of the Sex-Based Difference in Outcomes of COVID19 Infection

Front. Physiol. 12:627260. doi: 10.3389/fphys.2021.627260

\section{The Physiological Mechanisms of the Sex-Based Difference in Outcomes of COVID19 Infection}

\author{
Susan Wray* and Sarah Arrowsmith \\ Department of Women's and Children's Health, University of Liverpool, Liverpool, United Kingdom
}

The scale of the SARS-CoV-2 pandemic has thrust a spotlight on the sex-based differences in response to viral diseases; morbidity and mortality are greater in men than women. We outline the mechanisms by which being female offers a degree of protection from COVID19, that persists even when confounders such as comorbidities are considered. The physiological and immunological mechanisms are fascinating and range from incomplete $X$ chromosome inactivation of immune genes, a crucial role for angiotensin converting enzyme 2 (ACE2), and regulation of both immune activity and ACE2 by sex steroids. From this flows understanding of why lung and other organs are more susceptible to COVID19 damage in men, and how their distinct immunological landscapes need to be acknowledged to guide prognosis and treatment. Pregnancy, menopause, and hormone replacement therapy bring changed hormonal environments and the need for better stratification in COVID19 studies. We end by noting clinical trials based on increasing estrogens or progesterone or anti-testosterone drugs; excellent examples of translational physiology.

Keywords: steroid hormones, sexual dimorphism, SARS-CoV-2, pregnancy, ACE2, hormones

\section{INTRODUCTION}

This short review focuses on how differences in the physiology of women and men affect the outcome and survival of patients with COVID19. We first review the evidence that outcomes for females are more favorable, before considering the mechanisms and relating them to viral infection. We use the binary terms "male" and "female" so we can correctly report data in published studies, which so far have not considered if COVID19 has particular effects on trans and non-binary people.

\section{COVID19 Outcomes Are Worse in Males}

At the time of writing (October 2020), it is almost a year since the first reports of severe acute respiratory syndrome coronavirus 2 (SARS-CoV-2), which causes coronavirus-2019 (COVID19), appeared. Since then, there has been concerted international effort to understand the virus, the disease it produces and develop strategies to combat it. From the earliest findings, it emerged that more men than women suffer severe COVID19 disease and die from it (Jin et al., 2020; Pradhan and Olsson, 2020; Scully et al., 2020). This finding of men succumbing to more severe disease and dying, was also a feature in the two previous, smaller coronavirus diseases, Middle East Respiratory System (MERS-CoV) in 2012 and SARS-CoV in 2002 (Channappanavar et al., 2017; $\mathrm{Lu}$ et al., 2020). For SARS-CoV-2, with its global reach and high infectivity, the continued analysis of large global data sets of sex-disaggregated data has been possible, and the data are clear; women 
fare better with COVID19 (Raparelli et al., 2020; Williamson et al., 2020). For updated statistical information, from $\sim 180$ countries, the "COVID19 sex-disaggregated tracker update," from (https://globalhealth5050.org/the-sex-gender-and-covid19-project/) is recommended. Figure 1A is taken from their 19th October 2020 report and shows some clinical stages of COVID19 by sex. Examples of regional case fatality rates by sex can be seen in Figure 1B.

\section{Sex Differences Remain After Accounting for Infection Rates, Age, and Comorbidities}

With the increases in available data it is possible to interrogate the statistics further and ask whether differences such as infection rates, age and co-morbidities can explain the sex differences in the outcomes of COVID19, (Abate et al., 2020). It appears that none can. Infection rates are approximately similar in women and men throughout the world (Chakravarty et al., 2020; Williamson et al., 2020)-the effects of gender and social norms, are discussed below. The effects of COVID19, and death from it, are known to increase with age. This is true for both sexes, and a variety of explanations suggested, from access to hospital and intensive care facilities, comorbidities, and immunosenescence. The latter may be due to decline in sex hormones in both sexes (Gomez et al., 2019). Menopause is specifically addressed later. When however, COVID19 deaths rates are disaggregated by age and sex, the disproportionate effect on males remains, see Figure 1C. Like age, comorbidities also worsen the progress of the disease and fatalities from it. More men die even when these factors are adjusted for. A recent study undertaken to determine who is most at risk of a severe outcome from SAR-CoV-2 infection, used a health analytical platform to obtain data from $>17$ million patients in the UK, within which were almost 11,000 COVID19 deaths (Williamson et al., 2020). These deaths were associated with being male, and various medical conditions, including asthma and diabetes. A multivariate analysis confirmed the sex difference in deaths, even when adjusted for all other factors, including age, obesity and diseases (diabetes, cancer, kidney, asthma, and ten others). Although beyond the scope of this review, a substantially higher death rate was found in South Asian and black people compared to white people, that was only partially attributable to comorbidities and deprivation.

While future studies will further refine our knowledge concerning disease outcomes, sex makes a significant contribution to outcomes; in COVID19, women have a degree of protection compared to men. We are not saying that all the aspects of COVID19 can be attributed to sex differences, but rather, that benefits will follow from understanding the disease better, and biological sex is a part of this. We will briefly mention how gender may impact on these data, before a more detailed discussion of the physiological mechanisms of the reported sex differences.

\section{Gender}

There are many ways that gender can impact on COVID19 statistics. Compared to men, women may be more concerned about COVID19 (Brooks and Saad, 2020). This may lead to greater compliance with public health policies such as mask wearing, hand washing, and social distancing. In addition, globally women spend less time out of the home. These factors may reduce their infection rates, but are countered by the fact that they contribute significantly higher to the healthcare work force-an analysis of 104 countries by the World Health Organization in 2019 found that women represent around 70\% of the health workforce. Men may wait longer to seek a doctor after infection and therefore be sicker before treatment. In addition, more men are, or have been, smokers, drink alcohol and have cardiovascular disease. These factors will all increase susceptibility to COVID19, but as discussed earlier, cannot explain the findings of sex differences.

\section{MECHANISM FOR SEX DIFFERENCES DURING COVID19}

We first overview how SARS-CoV-2 infects humans as the basis for understanding how sex-based differences can arise. We then focus on the role of angiotensin converting enzyme 2 (ACE2) and infection, and then sex differences in immunological responses to infection.

\section{Overview of SARS-CoV-2}

Coronaviruses are large-enveloped, single stranded, positivesense RNA viruses. They contain transmembrane spike glycoproteins; composed of heads, which have host receptor binding domains and stalks, responsible for membrane fusion and infection of the host cell (Figure 2A). Compared to the 2003 SARS-CoV outbreak, SARS-CoV-2 is better able to evade our immune defenses and is highly infectious, hence the current pandemic. Both viruses use the receptor for ACE2 as their attachment target, starting in the lungs (Li et al., 2003; Tai et al., 2020; Figures $\mathbf{2 B}$, C. $^{1}$ That this is essential for viral entry was shown using ACE2 knock out mice (Kuba et al., 2005). Infection is associated with both shedding and down-regulation of the ACE2 receptor, which as discussed below, will have physiological consequences (Heurich et al., 2014; Figure 2D). The SARSCoV-2 virus has a higher binding affinity than SARS-CoV. For infection, the stalks must be activated, and this is achieved by proteases, specifically the host cell's transmembrane serine protease 2 (TMPRSS2, see Figure 2D; Belouzard et al., 2009). It has however been found that with SARS-CoV-2, there is an element of self-activation performed by the viral proprotein convertase furin. This facilitates SARS-CoV-2 entry, a property that it exploits in those cells that have low TMPRSS2 expression (Shang et al., 2020).

\section{ACE2}

Our knowledge of ACE2 and its relation to the classic reninangiotensin-aldosterone system (RAAS), is relatively recent; (Donoghue et al., 2000; Tipnis et al., 2000) see Figure 3 for a simple scheme. It has been labeled the protective

\footnotetext{
${ }^{1}$ https://scx1.b-cdn.net/csz/news/800/2020/whatistheace.jpg
} 


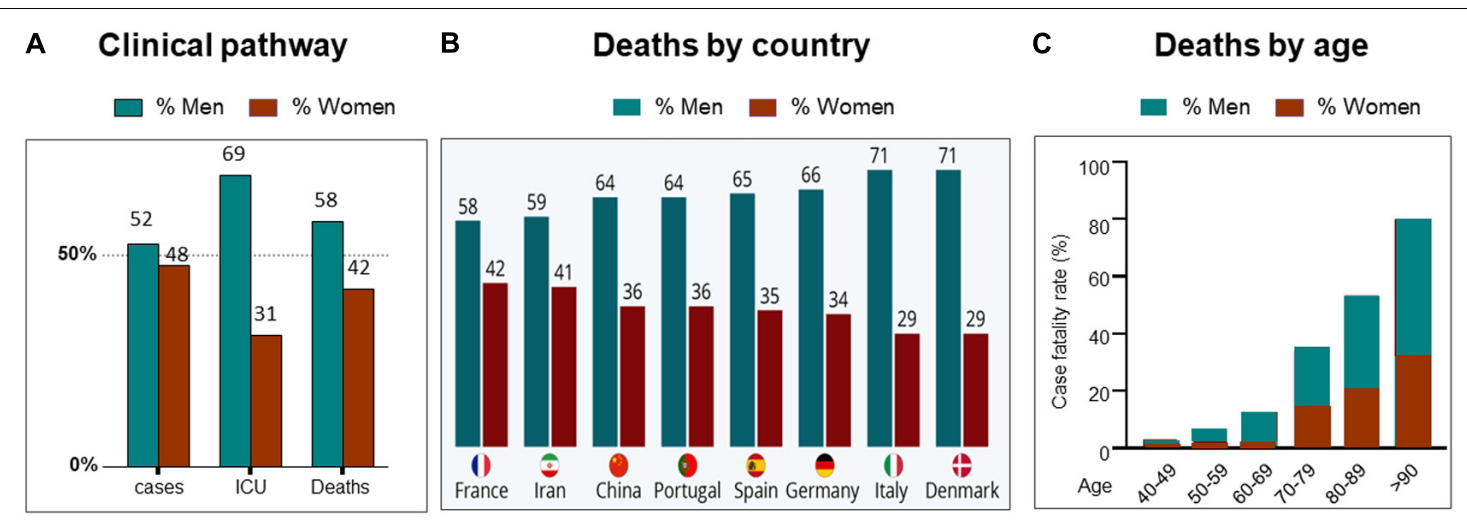

FIGURE 1 | Sex differences and COVID19. (A) Clinical pathway from confirmed cases, intensive care unit (ICU) admissions and deaths from COVID19. Data from countries providing sex-disaggregated data in October 2020. Redrawn from Global health 5050 at https:/globalhealth5050.org/wp-content/uploads/October-2020The-COVID-19-Sex-Disaggregated-Data-Tracker-Update.pdf, accessed October 16th 2020. (B) Covid19 deaths by country and sex, in March 2020. Chart from Statista at: https://www.statista.com/chart/21345/coronavirus-deaths-by-gender/. (C) deaths from COVID19 grouped by age and sex. Data obtained from 12 countries in May 2020. Redrawn from Global health 5050.

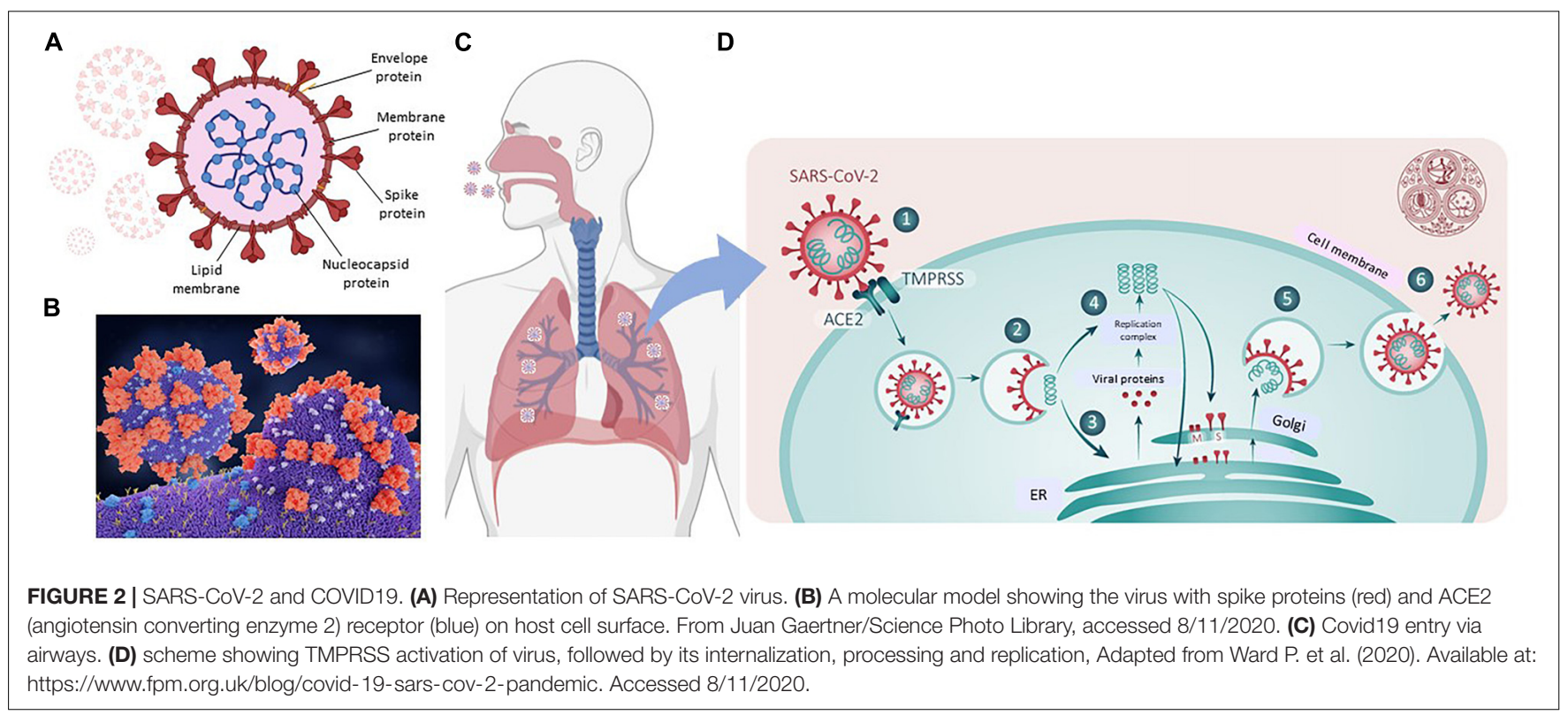

counter arm of RAAS as it has positive metabolic effects, and is vasodilating, anti-proliferation, and anti-inflammatory, balancing angiotensin II's vasoconstrictive role (White et al., 2019; Samavati and Uhal, 2020).

ACE2 is a zinc containing, carboxy peptidase that removes an amino acid and converts angiotensin 1 to angiotensin 19 and angiotensin 11 into the vasodilator, angiotensin(1-7), and may have additional substrates (Hamming et al., 2007; Figure 3). Its catalytic site is extracellular. ACE2 is cleaved from cells by metalloproteases such as ADAM10 and ADAM17 and is shed with an active catalytic site into plasma (Turner, 2015), see Figure 3). Men appear to have higher plasma ACE2 levels than women (see Salah and Mehta, 2020). Physiologically, Ang-(1-7) has been shown to signal via a novel GPCR, Mas (Bader et al., 2018). As infection produces a down-regulation of ACE2, this may contribute to the hypertension and inflammation seen with COVID19, as the vasodilator Ang(1-7) is decreased (Povlsen et al., 2020; Samavati and Uhal, 2020), and has led to the suggestion that exogenous ACE2 could be therapeutic (Verdecchia et al., 2020). ACE2 expression can be modulated by peptides and hypoxia (Melo Junior et al., 2020), and it and TMPRSS2 are modulated by steroid hormones (Baratchian et al., 2020; Young et al., 2020), as described next.

\section{ACE2, TMPRSS, and Sex}

Until menopause, women are relatively protected from a variety of cardiovascular risks, including high blood pressure (Reckelhoff, 2018). Part of the underlying reason for this is the effect of sex steroid hormones on RAAS, (Dalpiaz et al., 2015; Turner, 2015; Melo Junior et al., 2020). Although it seems reasonable to anticipate sex-based differences and regulation of ACE2, research is limited, especially on human tissues 


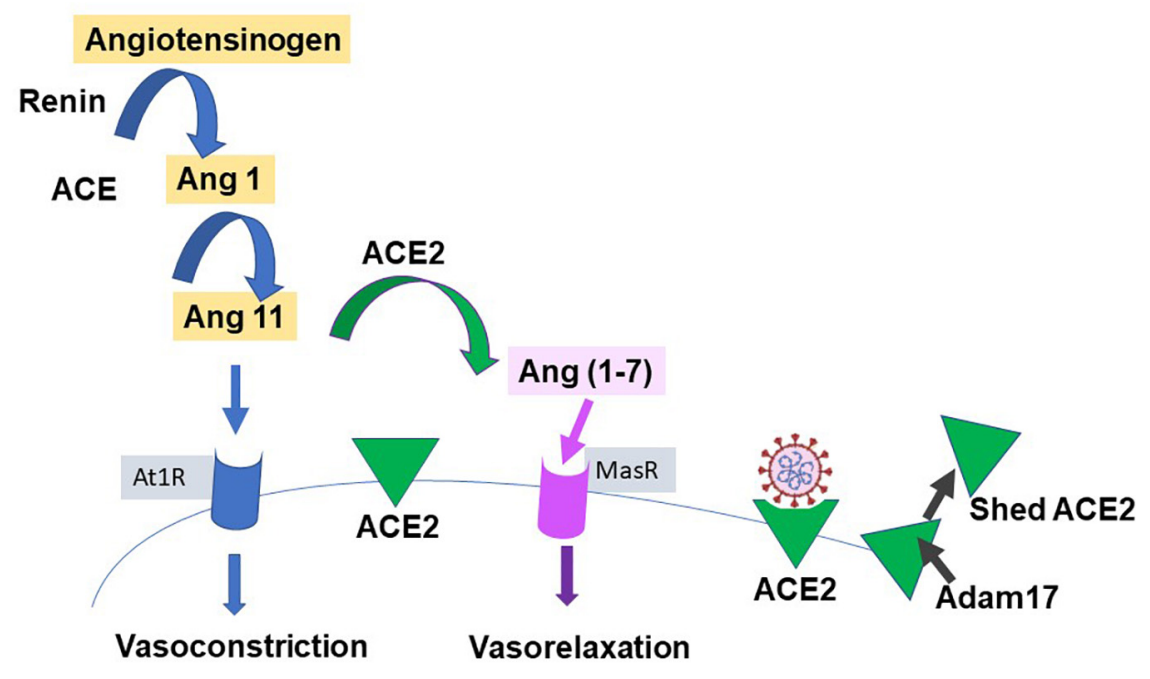

FIGURE 3 | Simplified renin-angiotensin system. Scheme shows the role of ACE2 as both the catalysis for Ang(1-7) creation, with a vasodilatory effect on vascular smooth muscle, and as the receptor for SARS-CoV-2. Proteases such as those of the Adam group act to cause shedding of ACE2 into plasma.

(Salah and Mehta, 2020; Samavati and Uhal, 2020; Song et al., 2020). With the COVID19 pandemic, attention has focused on ACE2 in the alveoli, but it has a wide tissue distribution. Specifically, it is only moderately expressed in lung, compared to kidney, heart, fat cells, and oral mucosa, and in comparable amounts to those reported in gut, bladder, brain and adrenals (Hamming et al., 2004; Zou et al., 2020). This tissue-wide distribution probably contributes to the multi organ pathologies brought on by infection. Of note with respect to COVID19, greater ACE2 expression was found in pneumocytes from men compared to women (Song et al., 2020). In differentiated human airway epithelial cells, treated either with vehicle or estradiol, the latter expressed lower levels of ACE2 mRNA (Stelzig et al., 2020) (TMPRSS2 mRNA levels were not affected). Estradiol may also positively regulates kidney, cardiac and adipose ACE2 expression (Gupte et al., 2012; Dalpiaz et al., 2015). In rats, both sexes have age-related declines in ACE2 expression, but to a greater extent in males (Xie et al., 2006). It is important to see if ACE2 transcript are translated to protein levels on the cell membrane, but it seems likely that there is sexual dimorphism in the availability of a key infectivity component, ACE2, necessary for COVID19.

TMPRSS2 is also widely distributed and highly expressed in epithelial cells in lungs, small intestine, heart, liver, and prostate. No significant difference in TMPRSS2 expression between males and females in human lung were found (Song et al., 2020). Its transcription and activity are controlled by androgens and discussed again in the section on males and COVID19.

Both epidemiological and experimental studies have reported sex differences in the therapeutic benefits of modulators of the RAAS pathway. It was noted that "Despite these differences, RAS inhibitors are the most commonly prescribed drugs for the treatment of chronic renal disease, irrespective of sex" (Sullivan, 2008). We consider that this point remains valid for therapeutic approaches using RAAS modulating drugs during COVID19, and could skew findings if not considered (Furuhashi et al., 2020; Reynolds et al., 2020; Young et al., 2020).

\section{IMMUNOLOGICAL RESPONSES AND SEX DIFFERENCES}

\section{Background}

During COVID19, immune cells in the lungs produce a "cytokine storm"; specifically, interleukin-6, interleukin-1 $\beta$, tumor necrosis factor $\alpha$, along with infiltration of chemokines, occurs. This hypercytokinemia and infiltration of monocytes and neutrophils, produces lung injury and respiratory difficulties. This pathological consequence of the immune response underlies the use of blockers of these cytokines as therapeutic approaches (Tang et al., 2020). These differences in male and female immunological activity can be related to their differing vulnerability to the disease.

Women and men differ in their physiological responses to viral diseases (Klein and Flanagan, 2016). Compared to males, females mount stronger immune responses to combat and clear viral loads (Klein, 2012). With vaccines this can lead to females producing over-exuberant responses, of both the innate and adaptive immune systems, estimated to be twice as strong as in males. This can cause increased adverse outcomes (Klein et al., 2010), as well as the increased incidence of auto-immune and inflammatory diseases found in females. Sex-dependent steroid hormones and genes, have been linked to the mechanism determining differences between the sexes in response to viral infection (Forsyth and Anguera, 2021). Many genes associated with immune responses are present on the $\mathrm{X}$ chromosome. Although in females one copy of these should be inactivated, there is evidence for gene imbalance, favoring females and their immunological responses to viral infections (Wang et al., 2016; Schurz et al., 2019). One example is Toll-like receptor 7 
(TLR7). The gene for this receptor which senses RNA viruses such as SARS-CoV-2, is present on the $\mathrm{X}$ chromosome and may escape X cell inactivation (Souyris et al., 2018). All types of immune cells have estrogen and progesterone receptors which will act as transcriptional regulators. The effects of testosterone on immune responses are not as marked as those of female hormones and there will only be one copy of the X chromosome. In addition, it has been speculated that microRNAs., which act as post-transcriptional modulators of gene expression, and are also regulated by sex hormones., may also contribute to sex-based differences, especially as the $\mathrm{X}$-chromosome has a particular abundance of microRNAs (see e.g., for further details Pontecorvi et al., 2020). Although too large a topic to be covered in detail here (Channappanavar et al., 2017; Jakovac, 2020), the protective effects of estrogen (and progesterone) have been attributed to (and see also Figure 5): (i) their promotion of production of anti-inflammatory cytokines (e.g., such as interleukins 4 and 10), (ii) increasing helper $\mathrm{T}$ cells, (iii) increasing $\mathrm{B}$ cells and thereby antibodies, and (iv) suppressing production of proinflammatory cytokines and migration of macrophages and monocytes into infected tissue (Mauvais-Jarvis et al., 2020).
These protective advantages decline with age. A different but related point concerns Vitamin $\mathrm{D}$, as it has been suggested that low levels of D3 may correlate with poorer infection outcomes. Estrogen may enhance vitamin D's actions, which include reducing the cytokine storm, and in this way contribute to sex-based differences (Pagano et al., 2020). A collection of papers covering endocrinology and COVID19 was published in $2020^{2}$. For a comprehensive account of the endocrinological effects on the immune system recent reviews are recommended (Gadi et al., 2020; Mauvais-Jarvis et al., 2020; Young et al., 2020). Thus, we expect that the immune landscape during a SARS-CoV2 infection will differ between men and women and make the former more vulnerable to COVID19.

Different inflammatory patterns are also thought to lead to different occurrences of cardiac arrhythmias which are also burdening patients with COVID-19. Systemic infection and inflammatory cytokines, such as IL-6, have been shown to prolong the QT-interval and alter

\footnotetext{
${ }^{2}$ https://www.frontiersin.org/research-topics/13975/endocrinology-and-covid-a-cross-disciplinary-topic\#articles
}
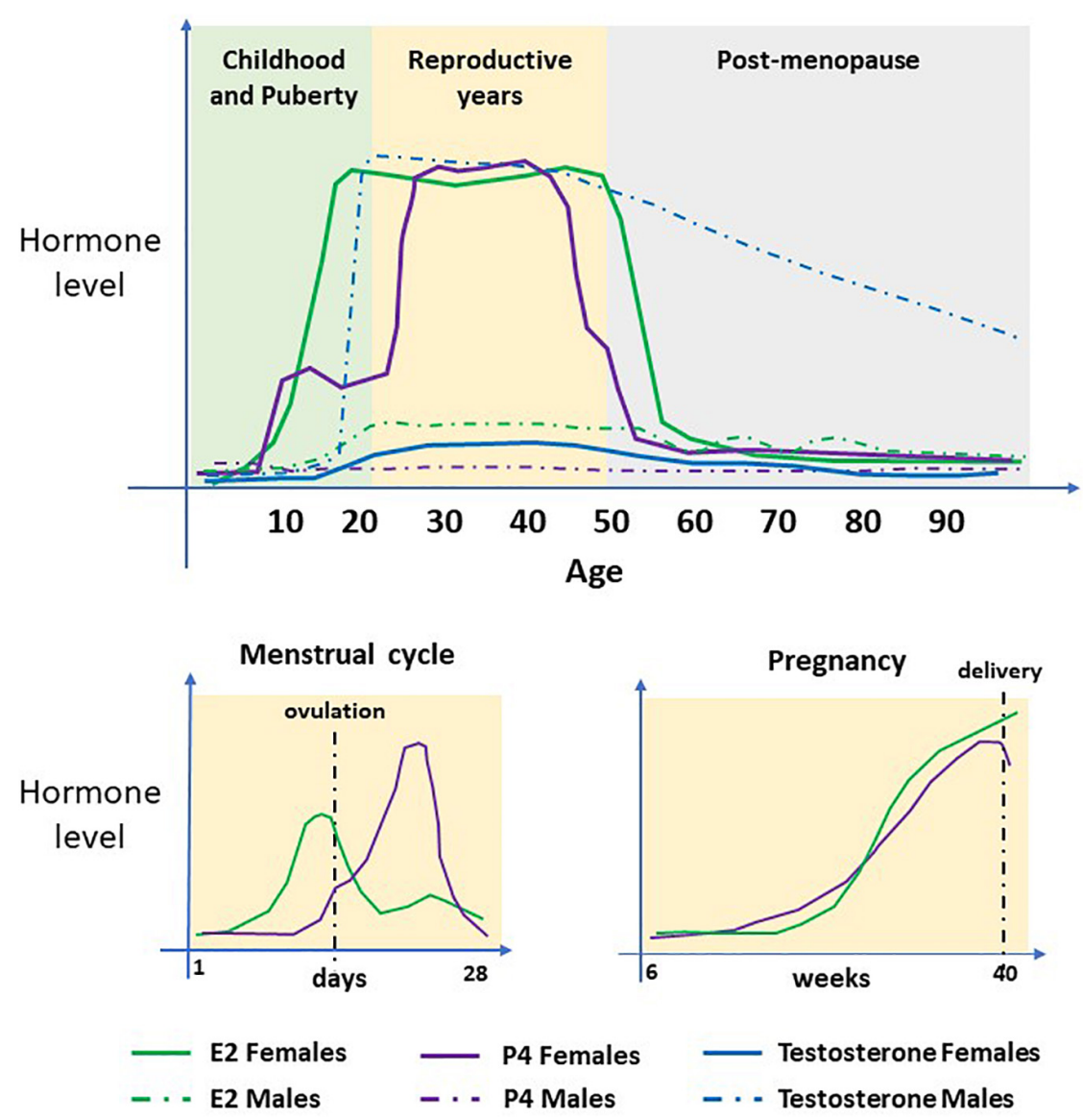

FIGURE 4 | Serum concentrations of sex steroid hormones. The hormones 17 $\beta$-estradiol (E2), Progesterone (P4) and Testosterone (T/DHT) in women and men during their life course. In females, E2 and P4 are the predominant hormones. Concentrations increase at puberty, undergo cyclical changes during the menstrual cycle and steadily increase during pregnancy. At menopause, concentrations decline to pre-puberty levels. T/DHT is the predominant male hormone which increases at puberty and remains high until late in life when levels decline steadily. 


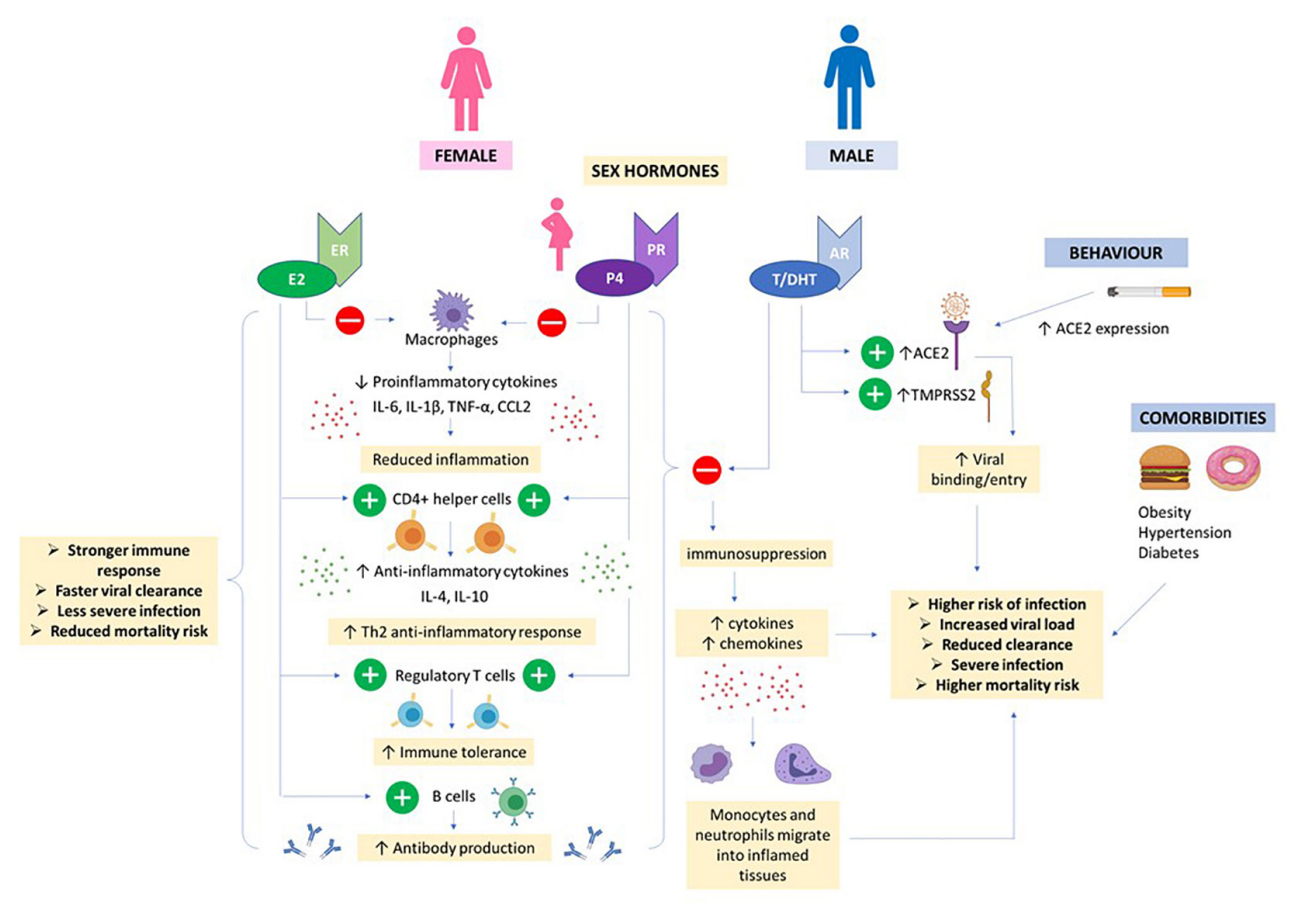

FIGURE 5 | Hormones and COVID19. High E2 and P4 concentrations in females (even higher in pregnancy) helps to suppress proinflammatory cytokine production by macrophages and prevent migration of monocytes and neutrophils into inflamed tissues. CD4 + helper cells are stimulated to produce anti-inflammatory cytokines and T regulatory cells promote immune tolerance. E2 also stimulates production of antibodies. Together, this results in a stronger immune response, faster viral clearance and less severe COVID infection in women. Androgens e.g., T/DHT and AR signaling increases expression of ACE2 and TMPRSS2 promoting viral entry. Together, T/DHT's immunosuppressive effects, male behavioral factors and co-morbidities can contribute to a more severe COVID infection and worse outcome in males.

repolarizations (Lazzerini et al., 2020a,b). Hence, sex-based differences in cytokine expression may also be attributing to differences in mortality rates via alterations in risk of life-threatening cardiac events.

\section{Immune Differences With COVID19}

Studies of lung injury have demonstrated increased damage in male mice and ovariectomized females, which could be reduced by estradiol administration (Speyer et al., 2005). Similar protective effects of estradiol and progesterone were observed in studies of influenza-infected animals (Robinson et al., 2011; Hall et al., 2016). When considering the role of the immune system in sex based COVID19 differences, a key question is whether they are due to differences in viral load, antibody response or plasma cytokines. With SARS female mice had lower viral loads, lower inflammatory responses, reduced lung damage and death, compared to males; this protection was lost with ovariectomy or treatment with the estrogen receptor antagonist, fulvestrant (Channappanavar et al., 2017). The detailed answers to how women and men differ in their immune responses to COVID19 has been directly addressed in a recent comprehensive study (Takahashi et al., 2020). Patients with a clinical diagnosis of moderate COVID19 who were not taking immunomodulatory medicines, were studied. No sex difference was found in viral RNA concentrations. Follow up of these patients found, however, that those females with higher salivary viral load deteriorated, whereas this correlation was not found in males. Males had higher plasma levels of immune cytokines of the innate immune system such as IL-8 and IL-18. Women had more robust T cell responses, which is consistent with findings during other infections (Amadori et al., 1995). This is an important difference, as a poor $\mathrm{T}$ cell response was associated with poor disease outcome in men but not in women. In women but not men, worse outcome was associated with high levels of innate immune cytokines. There were some innate immune factors, such as Il-15 that increased only in females who progressed to worse disease, an association not found in males. Women could benefit more from therapies that that dampened their innate immunity responses during initial infection period.

Thus, by disaggregating patient data by sex, key differences in the immune landscapes have been identified. This heterogeneity in immune capabilities and responses helps understanding of the distinct COVID19 progression in women and men, and may be used to guide disease prognosis and sex-specific treatments (Tang et al., 2020; Ursin et al., 2020). Of relevance here also is the use of COVID19 convalescent plasma donor therapy. As males tend to have more severe COVID19, their enhanced inflammatory responses and higher $\mathrm{B}$ cell recruitment, and antibodies, suggests that older males may be more useful plasma donors (Klein et al., 2020). As described below, the protective effects of estrogen and progesterone (or anti-testosterone treatments) have stimulated novel treatment trials. 


\section{PREGNANCY}

Pregnancy presents a unique and complex immunological scenario; the maternal immune system needs to be able to tolerate a "foreign" developing fetus whilst also protecting the mother against infections and favoring the transfer of maternal antibodies to the fetus. Elements of host defense and innate and adaptive immunity are altered during pregnancy to provide this co-operation (Racicot et al., 2014). Whilst protecting the fetus, this immune modulation could predispose pregnant women to increased susceptibility to infection from pathogens such as viruses (Robinson and Klein, 2012). Indeed, pregnant women have been shown to be disproportionately affected by respiratory illnesses, e.g., influenza (Robinson and Klein, 2012). During the MERS and SARS outbreaks, increased morbidity and higher maternal mortality rates were found (Wong et al., 2004). Hence during the current COVID19 pandemic, higher rates of mortality and disease severity were expected in pregnant women, and shielding was recommended.

The potential increased seriousness of COVID19 in pregnancy, however, has not been observed. So far, despite ACE2 being highly expressed in the placenta (Levy et al., 2008), vertical transmission to the fetus has not been seen (Chen $\mathrm{H}$. et al., 2020). There is no consensus of an effect on rates of miscarriage, stillbirth or preterm birth in COVID19-infected mothers (Dubey et al., 2020; Pettirosso et al., 2020). In terms of maternal morbidity and mortality, despite the heightened severity experienced in other viral diseases (Siston et al., 2010), studies so far have not put pregnant women at any greater risk of disease severity or complications from COVID19 compared to their non-pregnant counterparts (Chen L. et al., 2020; Collin et al., 2020). How these differences relate to the specific differences between the corona viruses has not been elucidated. Epidemics can lead to resources being removed from obstetrics, maternity, and sexual health, and diverted to emergency responses, and hence increasing maternal deaths, with or without infection.

\section{Physiological Protective Mechanisms and COVID19 in Pregnancy}

We know from sex-based studies that females mount a greater immune response to many viral infections and this is largely due to the protective and acute effects of estrogen (Robinson et al., 2011). In pregnancy, the concentrations of $17 \beta$-estradiol (E2), estriol (E3), and progesterone are significantly increased (see Figure 4). These hormonal changes underly the immunological changes required to provide a pregnancy-supportive immune environment, as well as stimulating antibody production by $\mathrm{B}$ cells. Both E2 and progesterone are known to alter the number and function of multiple immune cell types producing an immunologic switch from a pro- to an anti-inflammatory state, with T-helper 2 cell dominance elevating IL-4, IL-10, IL-13, and TGF-beta (Mauvais-Jarvis et al., 2020), see Figure 5).

These changes in the hormonal milieu which shift the cytokine signature toward an anti-inflammatory state in pregnancy, may support an early adaptive immune response which helps to blunt early COVID19 infection and inflammation. In turn, this would help prevent the "cytokine storm" and its associated pulmonary pathologies, in pregnant women infected with SARS-CoV-2.

Others have suggested that folic acid supplementation during pregnancy may provide protection (Acosta-Elias and EspinosaTanguma, 2020). Computer simulation studies indicated that folic acid can reduce viral replication by inhibiting its furin endoprotease (Coutard et al., 2020) which is part of SARS-CoV2 host cell entry mechanism or inhibit the coronavirus 3C-like protease, $3 \mathrm{CL}_{\text {pro }}$, (Serseg et al., 2020) required for its replication (Hsu et al., 2005). Hence the severity of infection may be inversely proportional to the concentration of folic acid but more work is required (Acosta-Elias and Espinosa-Tanguma, 2020).

As the data on COVID19 in pregnancy come from small studies and sometimes lack controls including age-matching, conclusion remains tentative but cautiously optimistic. Of note also, pregnant women may visit care settings frequently and so signs of infection may be detected and treated earlier.

\section{POST-MENOPAUSAL WOMEN}

That adult men of all ages and older women pose the highest risk of developing serious complications from COVID19 infection (Scully et al., 2020), again raises the question of the role of sex steroid hormones on infectivity. In women the increase in risk begins in their late 50s, see Figure 1C, around the time of the menopause (Ding et al., 2020), which is characterized by female sex hormone deficiency (Figure 4).

Animal studies of SARS-CoV and MERS, showed that absence of E2 signaling following ovariectomy or estrogen receptor antagonist treatment is associated with more severe disease in female mice (Channappanavar et al., 2017). Moreover, hormones associated with having a higher ovarian reserve (anti-Mullerian hormone and E2) negatively correlate with COVID severity (Ding et al., 2020), further suggesting that pre-menopausal women are protected.

Large-scale self-reported data obtained from the UK COVID19 symptom tracker application (C-19) showed a positive association between COVID19 and menopausal status, and a negative association with combined oral contraceptive pill use (Costeira et al., 2020), supporting the hypothesis that E2 offers protection against disease severity. Hormone replacement therapy (HRT) use, however, was positively associated with COVID19 symptoms. The route of administration, dose and type of HRT however, was not recorded and further investigations are needed (Gargaglioni and Marques, 2020). HRT is also usually only estrogenic and at physiological concentrations, whilst the combined oral contraceptive pill has E2 and progesterone and at supra-physiological concentrations.

\section{MEN}

The differences between men and women has been emphasized throughout. A few additional points can be made. Testosterone exerts immunosuppressive effects (Foo et al., 2017; Figure 5) 
which may contribute to a blunted antibody response in men and result in a worse prognosis compared to females (Chanana et al., 2020). Androgens, including testosterone, enhance expression of $\mathrm{TPMRSS}_{2}$ facilitating viral fusion with host cell membranes (Asselta et al., 2020; Hoffmann et al., 2020). Male sex hormones are also thought to increase the activity of the ACE2 receptor (Dalpiaz et al., 2015) further enabling SARS-COV-2 viral infectivity. Men with androgenetic alopecia or male pattern hair loss, a condition associated with genetic variations in the androgen receptor gene and signaling (Hillmer et al., 2005), are also thought to be at a greater risk of COVID19 severity: small studies have indicated high incidence of male pattern baldness in patients hospitalized with COVID19 (Goren et al., 2020). Along with the gender differences and detailed immunological differences reported in men with COVID19 disease discussed above, it is suggested that men will benefit from treatments that increase their $\mathrm{T}$ cell immune responses, and anti-testosterones.

\section{CLINICAL TRIALS}

A SARS-CoV-2 protein interaction study mapped many potential for repurposing drugs, including sex hormones (Gordon et al., 2020). That sex hormones can modulate inflammatory responses, lessen the cytokine storm or impede viral entry, has added to the suggestion that exogenous hormones could be administered as therapies, either prophylactically or as treatment adjuncts, to reduce COVID19 disease severity. Re-purposing of existing and already approved therapies is particularly exciting given there is little time to develop new ones.

In the USA, two trials are underway testing whether symptom severity can be reduced with either a short course of estradiol, administered by transdermal patch, in adult men and older women with COVID19 (NCT04359329) or oral progesterone in men (NCT04365127). In Mexico, a trial is investigating the effect of a combined estrogen and progesterone patch (NCT04539626) on clinical response and mortality in non-severe COVID19 patients. A trial in Iran is also testing the effect of injectable estradiol and testosterone on recovery in male and female COVID19 patients with respiratory, heart or kidney failure (IRCT20150716023235N15).

Trials exploring anti-androgen therapies are also underway, including in Sweden (NCT04475601), the USA (NCT04509999, NCT04374279) and Brazil (NCT04446429) with a view to reducing disease severity in older ( $>50$ years) male and female patients, or males presenting with male-pattern baldness, by inhibiting the expression of androgen regulated proteins, such as TMPRSS2. Other trials are investigating the effect of decreasing TMPRSS2 action using TMPRSS2 inhibitors (see Table 1).

In Italy, a Phase II randomized trial is planned to assess the efficacy of intravenous oxytocin in patients affected by COVID19 (NCT04386447). Oxytocin known for its role in augmenting uterine contractions in labor (Arrowsmith, 2020), has also been shown to limit excessive pro-inflammatory and oxidative stress

TABLE 1 | Clinical trial identifiers, drug class and targets.

\begin{tabular}{|c|c|c|c|c|}
\hline Drug class & Target & Action/effect & Trial identifier & Sponsor/location \\
\hline ER agonist & Estrogen Receptor & Increase estrogen and its effects & NCT04359329 & Stony Brook University Hospital, NY, USA \\
\hline ER modulator & Estrogen Receptor & $\begin{array}{l}\text { Decreases estrogen production } \\
\text { Increases testosterone production }\end{array}$ & NCT04389580* & Kafrelsheikh University Egypt \\
\hline P4 hormone & $\begin{array}{l}\text { Progesterone } \\
\text { Receptor }\end{array}$ & Increase progesterone and its effects & NCT04365127 & Cedars Sinai Medical Center, CA, USA \\
\hline E2/P4 combined & $\begin{array}{l}\text { Estrogen receptor } \\
\text { and progesterone } \\
\text { receptor }\end{array}$ & & NCT04539626 & Mexico \\
\hline Anti-Androgens & Androgen Receptor & Decrease androgens/androgen signaling & $\begin{array}{l}\text { NCT04374279 } \\
\text { NCT04475601 } \\
\text { NCT04509999 } \\
\text { NCT04446429 }\end{array}$ & $\begin{array}{l}\text { Johns Hopkins, MD, USA } \\
\text { Sweden } \\
\text { USA } \\
\text { Brazil }\end{array}$ \\
\hline LHRH antagonist & $\mathrm{GnRH}$ & Decrease androgens & NCT04397718 & $\begin{array}{l}\text { Los Angeles, Brooklyn, Manhattan, Seattle, } \\
\text { USA }\end{array}$ \\
\hline TMPRSS2 inhibitor & TMPRSS2 & Decrease TMPRSS2 action & $\begin{array}{l}\text { NCT04353284 } \\
\text { NCT04338906* } \\
\text { NCT04374019 } \\
\text { NCT04321096 } \\
\text { NCT04355052* } \\
\text { NCT04352400 } \\
\text { NCT04355026 } \\
\text { NCT04273763* } \\
\text { NCT04340349* }^{*}\end{array}$ & $\begin{array}{l}\text { Yale, USA } \\
\text { Heinrich-Heine University, Germany } \\
\text { University of Kentucky, KY, USA } \\
\text { University of Aarhus, Denmark } \\
\text { Sheba Medical Center, Israel } \\
\text { University Hospital Padova, Italy } \\
\text { General and Teaching Hospital Celje, } \\
\text { Slovenia } \\
\text { Wenzhou Medical University, China } \\
\text { Instituto Nacional de Rehabilitacion, Mexico }\end{array}$ \\
\hline $\begin{array}{l}\text { Aldosterone } \\
\text { antagonist }\end{array}$ & Androgen receptor & Decrease androgen signaling & NCT04345887 & Istanbul University, Turkey \\
\hline
\end{tabular}

*Denotes trial in combination with other treatment. 
reactions during infection by decreasing interleukin levels (Wang et al., 2015), as well as aiding nitric oxide signaling which promotes vasodilation (Thibonnier et al., 1999). Hence, oxytocin could also be used as prospective therapy for limiting COVID19 severity (Soumier and Sirigu, 2020).

\section{Vaccines}

Passive antibody therapy for COVID19 has already been discussed (Abraham, 2020). Many vaccines are in development, in the hope of providing protection against SARS-CoV-2. From all the above it is clear that sex will be important in the immune response to such vaccines. Women will mount stronger antibody and $\mathrm{T}$-cell responses and suffer worse adverse reactions. Thus, the dosage they may need of any vaccine will be less than for men. Earlier studies of the influenza vaccines have reported that the same magnitude of protective immunity is achieved by half the dose in women compared to men (Klein, 2012). If vaccine against SARS-CoV-2 is in short supply initially, would it be ethical to give smaller shots to women?

\section{CONCLUSION}

Our main conclusion is that the sex-based differences in outcomes of COVID19 infection, tentatively reported at the beginning of the pandemic, have been reinforced by all subsequent studies. In addition, our understanding of the possible contributors to this is increasing but it is likely more exciting discoveries remain to be made., especially around the intersection of physiology, immunology and environmental factors.

We note that, generally, more men are enrolled in clinical trials and research in animals is often focused on males to avoid the cyclic fluctuations in hormones. This poses a significant barrier in understanding the sex-based differences in infection severity. The disparity in the effects of COVID19 observed between the sexes, and recent data in other physiological systems and pathologies, highlights the need to include both males and females in future research. There is clearly much more to be understood about sex-based differences. Understanding the mechanisms behind them may help to find appropriate and sex specific therapies

\section{REFERENCES}

Abate, B. B., Kassie, A. M., Kassaw, M. W., Aragie, T. G., and Masresha, S. A. (2020). Sex difference in coronavirus disease (COVID-19): a systematic review and meta-analysis. BMJ Open 10:e040129. doi: 10.1136/bmjopen-2020-040129

Abraham, J. (2020). Passive antibody therapy in COVID-19. Nat. Rev. Immunol. 20, 401-403. doi: 10.1038/s41577-020-0365-7

Acosta-Elias, J., and Espinosa-Tanguma, R. (2020). The folate concentration and/or folic acid metabolites in plasma as factor for COVID19 infection. Front. Pharmacol. 11:1062. doi: 10.3389/fphar.2020. 01062

Amadori, A., Zamarchi, R., De Silvestro, G., Forza, G., Cavatton, G., Danieli, G. A., et al. (1995). Genetic control of the CD4/CD8 T-cell ratio in humans. Nat. Med. 1, 1279-1283. doi: 10.1038/nm1295-1279

Arrowsmith, S. (2020). Oxytocin and vasopressin signalling and myometrial contraction. Curr. Opin. Physiol. 13, 62-70. doi: 10.1016/j.cophys.2019.10.006 for COVID19 and other sexually dimorphic pathologies (Bischof et al., 2020; Bunders and Altfeld, 2020).

\section{AUTHOR NOTES}

Biological sex affects areas of physiology and pathophysiology, beyond the obvious. Importantly these sex-based differences impact on both symptoms of disease and effectiveness of medication. In the light of the COVID19 pandemic, an appreciation of how the physiological and immunological differences between female and male responses to viral diseases is crucial, and it is to this that this review contributes. Compared to males, females mount stronger immune responses to combat and clear viral loads, but also have different immunological landscape during infection. Sex-dependent steroid hormones link mechanisms between sex and response to viral infection. For example, estrogens promote the production of anti-inflammatory cytokines, and having two $\mathrm{X}$ chromosomes can increase activity of immune genes carried on the chromosome, due to incomplete $\mathrm{X}$-inactivation. The host viral receptor is angiotensin converting enzyme 2 (ACE2). Sex differences in ACE2's expression in lungs and viral handling, are being actively investigated to better understand the underlying mechanisms. These differences have manifested worldwide in fewer deaths and severe COVID19 complication in females compared to males, despite roughly equal infection rates. They have also led to active clinical trials of using sex hormone treatments, such as estradiol patches, to help mitigate the effects of COVID19.

\section{AUTHOR CONTRIBUTIONS}

SW conceived the study. SW and SA wrote and edited the article. Both authors contributed to the article and approved the submitted version.

\section{FUNDING}

We are grateful to Harris- Wellbeing Centre for Women's Health Research for supporting this work.

Asselta, R., Paraboschi, E. M., Mantovani, A., and Duga, S. (2020). ACE2 and TMPRSS2 variants and expression as candidates to sex and country differences in COVID-19 severity in Italy. Aging 12, 10087-10098. doi: 10.18632/aging. 103415

Bader, M., Alenina, N., Young, D., Santos, R. A. S., and Touyz, R. M. (2018). The meaning of Mas. Hypertension 72, 1072-1075. doi: 10.1161/hypertensionaha. 118.10918

Baratchian, M., Mcmanus, J. M., Berk, M., Nakamura, F., Mukhopadhyay, S., Xu, W., et al. (2020). Sex, androgens and regulation of pulmonary AR, TMPRSS2 and ACE2. bioRxiv [Preprint], doi: 10.1101/2020.04.21.051201

Belouzard, S., Chu, V. C., and Whittaker, G. R. (2009). Activation of the Sars coronavirus spike protein via sequential proteolytic cleavage at two distinct sites. Proc. Natl. Acad. Sci. U.S.A. 106, 5871-5876. doi: 10.1073/pnas. 0809524106

Bischof, E., Wolfe, J., and Klein, S. L. (2020). Clinical trials for COVID-19 should include sex as a variable. J. Clin. Invest. 130, 3350-3352. doi: 10.1172/jci139306 
Brooks, D. J., and Saad, L. (2020). Double whammy: why the underrepresentation of women among workplace and political decision makers matters in pandemic times. Polit. Gend. 16, 1-13. doi: 10.2307/j.ctv301fkq. 6

Bunders, M. J., and Altfeld, M. (2020). Implications of sex differences in immunity for SARS-CoV-2 pathogenesis and design of therapeutic interventions. Immunity 53, 487-495. doi: 10.1016/j.immuni.2020.08.003

Chakravarty, D., Nair, S. S., Hammouda, N., Ratnani, P., Gharib, Y., Wagaskar, V., et al. (2020). Sex differences in SARS-CoV-2 infection rates and the potential link to prostate cancer. Commun. Biol. 3:374.

Chanana, N., Palmo, T., Sharma, K., Kumar, R., Graham, B. B., and Pasha, Q. (2020). Sex-derived attributes contributing to SARS-CoV-2 mortality. Am. J. Physiol. Endocrinol. Metab. 319, E562-E567.

Channappanavar, R., Fett, C., Mack, M., Ten Eyck, P. P., Meyerholz, D. K., and Perlman, S. (2017). Sex-based differences in susceptibility to severe acute respiratory syndrome Coronavirus Infection. J. Immunol. 198, 4046-4053. doi: 10.4049/jimmunol.1601896

Chen, H., Guo, J., Wang, C., Luo, F., Yu, X., Zhang, W., et al. (2020). Clinical characteristics and intrauterine vertical transmission potential of COVID-19 infection in nine pregnant women: a retrospective review of medical records. Lancet 395, 809-815. doi: 10.1016/s0140-6736(20)30360-3

Chen, L., Li, Q., Zheng, D., Jiang, H., Wei, Y., Zou, L., et al. (2020). Clinical characteristics of pregnant women with COVID-19 in Wuhan, China. N. Engl. J. Med. 382:e100. doi: 10.1056/nejmc2009226

Collin, J., Byström, E., Carnahan, A., and Ahrne, M. (2020). Public health agency of Sweden's brief report: pregnant and postpartum women with severe acute respiratory syndrome coronavirus 2 infection in intensive care in Sweden. Acta Obstet. Gynecol. Scand. 99, 819-822. doi: 10.1111/aogs.13901

Costeira, R., Lee, K. A., Murray, B., Christiansen, C., Castillo-Fernandez, J., Ni Lochlainn, M., et al. (2020). Estrogen and COVID-19 symptoms: associations in women from the COVID symptom study. medRxiv [Preprint], doi: 10.1101/ 2020.07.30.20164921v3

Coutard, B., Valle, C., De Lamballerie, X., Canard, B., Seidah, N. G., and Decroly, E. (2020). The spike glycoprotein of the new coronavirus 2019-nCoV contains a furin-like cleavage site absent in $\mathrm{CoV}$ of the same clade. Antiviral Res. 176:104742. doi: 10.1016/j.antiviral.2020.104742

Dalpiaz, P. L., Lamas, A. Z., Caliman, I. F., Ribeiro, R. F. Jr., and Abreu, G. R. (2015). Sex hormones promote opposite effects on ACE and ACE2 activity, hypertrophy and cardiac contractility in spontaneously hypertensive rats. PLoS One 10:e0127515. doi: 10.1371/journal.pone.0127515

Ding, T., Zhang, J., Wang, T., Cui, P., Chen, Z., Jiang, J., et al. (2020). Potential influence of menstrual status and sex hormones on female SARS-CoV-2 infection: a cross-sectional study from multicentre in Wuhan, China. Clin. Infect. Dis. 2020:ciaa1022.

Donoghue, M., Hsieh, F., Baronas, E., Godbout, K., Gosselin, M., Stagliano, N., et al. (2000). A novel angiotensin-converting enzyme-related carboxypeptidase (ACE2) converts angiotensin I to angiotensin 1-9. Circ. Res. 87, E1-E9.

Dubey, P., Reddy, S. Y., Manuel, S., and Dwivedi, A. K. (2020). Maternal and neonatal characteristics and outcomes among COVID-19 infected women: an updated systematic review and meta-analysis. Eur. J. Obstet. Gynecol. Reprod. Biol. 252, 490-501. doi: 10.1016/j.ejogrb.2020.07.034

Foo, Y. Z., Nakagawa, S., Rhodes, G., and Simmons, L. W. (2017). The effects of sex hormones on immune function: a meta-analysis. Biol. Rev. Camb. Philos. Soc. 92, 551-571. doi: 10.1111/brv.12243

Forsyth, K. S., and Anguera, M. C. (2021). Time to get ill: the intersection of viral infections, sex, and the X chromosome. Curr. Opin. Physiol. 19, 62-72. doi: 10.1016/j.cophys.2020.09.015

Furuhashi, M., Moniwa, N., Takizawa, H., Ura, N., and Shimamoto, K. (2020). Potential differential effects of renin-angiotensin system inhibitors on SARSCoV-2 infection and lung injury in COVID-19. Hypertens. Res. 43, 837-840. doi: 10.1038/s41440-020-0478-1

Gadi, N., Wu, S. C., Spihlman, A. P., and Moulton, V. R. (2020). What's sex got to do with COVID-19? gender-based differences in the host immune response to Coronaviruses. Front. Immunol. 11:2147. doi: 10.3389/fimmu.2020.02147

Gargaglioni, L. H., and Marques, D. A. (2020). Let's talk about sex in the context of COVID-19. J. Appl. Physiol. 128, 1533-1538. doi: 10.1152/japplphysiol.00335. 2020

Gomez, C. R., Nomellini, V., and Kovacs, E. J. (2019). "Sex hormones and immunosenescence," in Handbook of Immunosenescence: Basic Understanding and Clinical Implications, eds T. Fulop, C. Franceschi, K. Hirokawa, and G. Pawelec (Cham: Springer International Publishing).

Gordon, D. E., Jang, G. M., Bouhaddou, M., Xu, J., Obernier, K., White, K. M., et al. (2020). A SARS-CoV-2 protein interaction map reveals targets for drug repurposing. Nature 583, 459-468.

Goren, A., Vaño-Galván, S., Wambier, C. G., Mccoy, J., Gomez-Zubiaur, A., Moreno-Arrones, O. M., et al. (2020). A preliminary observation: male pattern hair loss among hospitalized COVID-19 patients in Spain - A potential clue to the role of androgens in COVID-19 severity. J. Cosmet. Dermatol. 19, 1545-1547. doi: 10.1111/jocd.13443

Gupte, M., Thatcher, S. E., Boustany-Kari, C. M., Shoemaker, R., Yiannikouris, F., Zhang, X., et al. (2012). Angiotensin converting enzyme 2 contributes to sex differences in the development of obesity hypertension in C57BL/6 mice. Arterioscler. Thromb. Vasc. Biol. 32, 1392-1399. doi: 10.1161/atvbaha.112. 248559

Hall, O. J., Limjunyawong, N., Vermillion, M. S., Robinson, D. P., Wohlgemuth, N., Pekosz, A., et al. (2016). Progesterone-based therapy protects against influenza by promoting lung repair and recovery in females. PloS Pathog. 12:e1005840. doi: 10.1371/journal.pone. 01005840

Hamming, I., Cooper, M. E., Haagmans, B. L., Hooper, N. M., Korstanje, R., Osterhaus, A. D., et al. (2007). The emerging role of ACE2 in physiology and disease. J. Pathol. 212, 1-11. doi: 10.1002/path.2162

Hamming, I., Timens, W., Bulthuis, M. L., Lely, A. T., Navis, G., and Van Goor, H. (2004). Tissue distribution of ACE2 protein, the functional receptor for Sars coronavirus. A first step in understanding Sars pathogenesis. J. Pathol. 203, 631-637. doi: 10.1002/path.1570

Heurich, A., Hofmann-Winkler, H., Gierer, S., Liepold, T., Jahn, O., and Pöhlmann, S. (2014). TMPRSS2 and Adam 17 cleave ACE2 differentially and only proteolysis by TMPRSS 2 augments entry driven by the severe acute respiratory syndrome coronavirus spike protein. J. Virol. 88, 1293-1307. doi: 10.1128/jvi. 02202-13

Hillmer, A. M., Hanneken, S., Ritzmann, S., Becker, T., Freudenberg, J., Brockschmidt, F. F., et al. (2005). Genetic variation in the human androgen receptor gene is the major determinant of common early-onset androgenetic alopecia. Am. J. Hum. Genet. 77, 140-148. doi: 10.1086/431425

Hoffmann, M., Kleine-Weber, H., Schroeder, S., Krüger, N., Herrler, T., Erichsen, S., et al. (2020). SARS-CoV-2 cell entry depends on ACE2 and TMPRSS2 and is blocked by a clinically proven protease inhibitor. Cell 181, 271-280.e8.

Hsu, M. F., Kuo, C. J., Chang, K. T., Chang, H. C., Chou, C. C., Ko, T. P., et al. (2005). Mechanism of the maturation process of SARS-CoV 3CL protease. J. Biol. Chem. 280, 31257-31266. doi: 10.1074/jbc.m502577200

Jakovac, H. (2020). Sex differences in COVID-19 course and outcome: progesterone should not be neglected. J. Appl. Physiol. 129, 1007-1008. doi: 10.1152/japplphysiol.00740.2020

Jin, J. M., Bai, P., He, W., Wu, F., Liu, X. F., Han, D. M., et al. (2020). Gender differences in patients with COVID-19: focus on severity and mortality. Front. Public Health 8:152. doi: 10.3389/fpubh.2020.00152

Klein, S. L. (2012). Sex influences immune responses to viruses, and efficacy of prophylaxis and treatments for viral diseases. Bioessays 34, 1050-1059. doi: 10.1002/bies.201200099

Klein, S. L., and Flanagan, K. L. (2016). Sex differences in immune responses. Nat. Rev. Immunol. 16, 626-638. doi: 10.1038/nri.2016.90

Klein, S. L., Jedlicka, A., and Pekosz, A. (2010). The Xs and Y of immune responses to viral vaccines. Lancet Infect. Dis. 10, 338-349. doi: 10.1016/s1473-3099(10) 70049-9

Klein, S. L., Pekosz, A., Park, H. S., Ursin, R. L., Shapiro, J. R., Benner, S. E., et al. (2020). Sex, age, and hospitalization drive antibody responses in a COVID-19 convalescent plasma donor population. J. Clin. Invest. 130, 6141-6150. doi: $10.1172 /$ jci142004

Kuba, K., Imai, Y., Rao, S., Gao, H., Guo, F., Guan, B., et al. (2005). A crucial role of angiotensin converting enzyme 2 (ACE2) in Sars coronavirus-induced lung injury. Nat. Med. 11, 875-879. doi: 10.1038/nm1267

Lazzerini, P. E., Boutjdir, M., and Capecchi, P. L. (2020a). COVID-19, arrhythmic risk, and inflammation: mind the Gap! Circulation 142, 7-9. doi: 10.1161/ circulationaha.120.047293

Lazzerini, P. E., Laghi-Pasini, F., Acampa, M., Boutjdir, M., and Leopoldo Capecchi, P. (2020b). IL-6 (Interleukin 6) blockade and heart rate corrected QT interval prolongation in COVID-19. Circ. Arrhythm Electrophysiol. 13:e008791. 
Levy, A., Yagil, Y., Bursztyn, M., Barkalifa, R., Scharf, S., and Yagil, C. (2008). ACE2 expression and activity are enhanced during pregnancy. Am. J. Physiol. Regul. Integr. Comp. Physiol. 295, R1953-R1961.

Li, W., Moore, M. J., Vasilieva, N., Sui, J., Wong, S. K., Berne, M. A., et al. (2003). Angiotensin-converting enzyme 2 is a functional receptor for the Sars coronavirus. Nature 426, 450-454.

Lu, L., Zhong, W., Bian, Z., Li, Z., Zhang, K., Liang, B., et al. (2020). A comparison of mortality-related risk factors of COVID-19, SARS, and MERS: a systematic review and meta-analysis. J. Infect. 81, e18-e25.

Mauvais-Jarvis, F., Klein, S. L., and Levin, E. R. (2020). Estradiol, Progesterone, Immunomodulation, and COVID-19 Outcomes. Endocrinology 161:bqaa127.

Melo Junior, A. F., Dalpiaz, P. L. M., Escouto, L. D. S., Sousa, G. J., Aires, R., Oliveira, N. D., et al. (2020). Involvement of sex hormones, oxidative stress, ACE and ACE2 activity in the impairment of renal function and remodelling in SHR. Life Sci. 257:118138. doi: 10.1016/j.lfs.2020.118138

Pagano, M. T., Peruzzu, D., Ruggieri, A., Ortona, E., and Gagliardi, M. C. (2020). Vitamin D and Sex Differences in COVID-19. Front. Endocrinol. 11:567824. doi: $10.3389 /$ fendo.2020.567824

Pettirosso, E., Giles, M., Cole, S., and Rees, M. (2020). COVID-19 and pregnancy: a review of clinical characteristics, obstetric outcomes and vertical transmission. Aust. N. Z. J. Obstet. Gynaecol. 60, 640-659. doi: 10.1111/ajo.13204

Pontecorvi, G., Bellenghi, M., Ortona, E., and Carè, A. (2020). microRNAs as new possible actors in gender disparities of COVID-19 pandemic. Acta Physiol. 230:e13538.

Povlsen, A. L., Grimm, D., Wehland, M., Infanger, M., and Krüger, M. (2020). The vasoactive Mas receptor in essential hypertension. J. Clin. Med. 9:267. doi: $10.3390 /$ jcm 9010267

Pradhan, A., and Olsson, P. E. (2020). Sex differences in severity and mortality from COVID-19: are males more vulnerable? Biol. Sex Differ. 11:53.

Racicot, K., Kwon, J. Y., Aldo, P., Silasi, M., and Mor, G. (2014). Understanding the complexity of the immune system during pregnancy. Am. J. Reprod. Immunol. 72, 107-116. doi: 10.1111/aji.12289

Raparelli, V., Palmieri, L., Canevelli, M., Pricci, F., Unim, B., Lo Noce, C., et al. (2020). Sex differences in clinical phenotype and transitions of care among individuals dying of COVID-19 in Italy. Biol. Sex Differ. 11, 57.

Reckelhoff, J. F. (2018). Sex differences in regulation of blood pressure. Adv. Exp. Med. Biol. 1065, 139-151. doi: 10.1007/978-3-319-77932-4_9

Reynolds, H. R., Adhikari, S., Pulgarin, C., Troxel, A. B., Iturrate, E., Johnson, S. B., et al. (2020). Renin-angiotensin-aldosterone system inhibitors and risk of COVID-19. N. Engl. J. Med. 382, 2441-2448.

Robinson, D. P., and Klein, S. L. (2012). Pregnancy and pregnancy-associated hormones alter immune responses and disease pathogenesis. Horm. Behav. 62, 263-271. doi: 10.1016/j.yhbeh.2012.02.023

Robinson, D. P., Lorenzo, M. E., Jian, W., and Klein, S. L. (2011). Elevated 17 $\beta$ estradiol protects females from influenza A virus pathogenesis by suppressing inflammatory responses. PLoS Pathog. 7:e1002149. doi: 10.1371/journal.pone. 1002149

Salah, H. M., and Mehta, J. L. (2020). Hypothesis: sex-related differences in ACE2 activity may contribute to higher mortality in men versus women with COVID-19. J. Cardiovasc. Pharmacol. Ther. 2020:1074248420967792.

Samavati, L., and Uhal, B. D. (2020). ACE2, much more than just a receptor for SARS-COV-2. Front. Cell Infect. Microbiol. 10:317. doi: 10.3389/fcimb.2020. 00317

Schurz, H., Salie, M., Tromp, G., Hoal, E. G., Kinnear, C. J., and Möller, M. (2019). The X chromosome and sex-specific effects in infectious disease susceptibility. Hum. Genom. 13:2.

Scully, E. P., Haverfield, J., Ursin, R. L., Tannenbaum, C., and Klein, S. L. (2020). Considering how biological sex impacts immune responses and COVID19 outcomes. Nat. Rev. Immunol. 20, 442-447. doi: 10.1038/s41577-0200348-8

Serseg, T., Benarous, K., and Yousfi, M. (2020). Hispidin and Lepidine E: two natural compounds and folic acid as potential inhibitors of 2019-novel coronavirus Main Protease (2019-nCovmpro), molecular docking and SAR study. Curr. Comput. Aided Drug Des. doi: 10.2174/ 1573409916666200422075440

Shang, J., Wan, Y., Luo, C., Ye, G., Geng, Q., Auerbach, A., et al. (2020). Cell entry mechanisms of SARS-CoV-2. Proc. Natl. Acad. Sci. U.S.A. 117, $11727-11734$.
Siston, A. M., Rasmussen, S. A., Honein, M. A., Fry, A. M., Seib, K., Callaghan, W. M., et al. (2010). Pandemic 2009 influenza A(H1N1) virus illness among pregnant women in the United States. JAMA 303, 1517-1525. doi: 10.1001/ jama.2010.479

Song, H., Seddighzadeh, B., Cooperberg, M. R., and Huang, F. W. (2020). Expression of ACE2, the SARS-CoV-2 receptor, and TMPRSS2 in prostate epithelial cells. Eur. Urol. 78, 296-298. doi: 10.1016/j.eururo.2020. 04.065

Soumier, A., and Sirigu, A. (2020). Oxytocin as a potential defence against COVID19? Med. Hypothes. 140:109785. doi: 10.1016/j.mehy.2020.109785

Souyris, M., Cenac, C., Azar, P., Daviaud, D., Canivet, A., Grunenwald, S., et al. (2018). TLR7 escapes X chromosome inactivation in immune cells. Sci. Immunol. 3:eaa8855.

Speyer, C. L., Rancilio, N. J., Mcclintock, S. D., Crawford, J. D., Gao, H., Sarma, J. V., et al. (2005). Regulatory effects of estrogen on acute lung inflammation in mice. Am. J. Physiol. Cell Physiol. 288, C881-C890.

Stelzig, K. E., Canepa-Escaro, F., Schiliro, M., Berdnikovs, S., Prakash, Y. S., and Chiarella, S. E. (2020). Estrogen regulates the expression of SARS-CoV-2 receptor ACE2 in differentiated airway epithelial cells. Am. J. Physiol. Lung Cell Mol. Physiol. 318, L1280-L1281.

Sullivan, J. C. (2008). Sex and the renin-angiotensin system: inequality between the sexes in response to RAS stimulation and inhibition. Am. J. Physiol. Regul. Integr. Comp. Physiol. 294, R1220-R1226.

Tai, W., He, L., Zhang, X., Pu, J., Voronin, D., Jiang, S., et al. (2020). Characterization of the receptor-binding domain (RBD) of 2019 novel coronavirus: implication for development of RBD protein as a viral attachment inhibitor and vaccine. Cell Mol. Immunol. 17, 613-620. doi: 10.1038/s41423020-0400-4

Takahashi, T., Ellingson, M. K., Wong, P., Israelow, B., Lucas, C., Klein, J., et al. (2020). Sex differences in immune responses that underlie COVID-19 disease outcomes. Nature 588, 315-320.

Tang, Y., Liu, J., Zhang, D., Xu, Z., Ji, J., and Wen, C. (2020). Cytokine storm in COVID-19: the current evidence and treatment strategies. Front. Immunol. 11:1708. doi: 10.3389/fimmu.2020.01708

Thibonnier, M., Conarty, D. M., Preston, J. A., Plesnicher, C. L., Dweik, R. A., and Erzurum, S. C. (1999). Human vascular endothelial cells express oxytocin receptors. Endocrinology 140, 1301-1309. doi: 10.1210/endo.140.3. 6546

Tipnis, S. R., Hooper, N. M., Hyde, R., Karran, E., Christie, G., and Turner, A. J. (2000). A human homolog of angiotensin-converting enzyme. Cloning and functional expression as a captopril-insensitive carboxypeptidase. J. Biol. Chem. $275,33238-33243$.

Turner, A. J. (2015). ACE2 cell biology, regulation, and physiological functions. Protect. Arm Renin Angioten. Syst. 2015, 185-189. doi: 10.1016/b978-0-12801364-9.00025-0

Ursin, R. L., Shapiro, J. R., and Klein, S. L. (2020). Sex-biased immune responses following SARS-CoV-2 Infection. Trends Microbiol. 28, 952-954. doi: 10.1016/ j.tim.2020.10.002

Verdecchia, P., Cavallini, C., Spanevello, A., and Angeli, F. (2020). The pivotal link between ACE2 deficiency and SARS-CoV-2 infection. Eur. J. Intern. Med. 76, 14-20. doi: 10.1016/j.ejim.2020.04.037

Wang, J., Syrett, C. M., Kramer, M. C., Basu, A., Atchison, M. L., and Anguera, M. C. (2016). Unusual maintenance of X chromosome inactivation predisposes female lymphocytes for increased expression from the inactive X. Proc. Natl. Acad. Sci. U.S.A. 113, E2029-E2038.

Wang, P., Yang, H. P., Tian, S., Wang, L., Wang, S. C., Zhang, F., et al. (2015). Oxytocin-secreting system: A major part of the neuroendocrine center regulating immunologic activity. J. Neuroimmunol. 289, 152-161. doi: 10.1016/ j.jneuroim.2015.11.001

White, M. C., Fleeman, R., and Arnold, A. C. (2019). Sex differences in the metabolic effects of the renin-angiotensin system. Biol. Sex Differ. 10:31.

Williamson, E. J., Walker, A. J., Bhaskaran, K., Bacon, S., Bates, C., Morton, C. E., et al. (2020). Factors associated with COVID-19-related death using Opensafely. Nature 584, 430-436.

Wong, S. F., Chow, K. M., Leung, T. N., Ng, W. F., Ng, T. K., Shek, C. C., et al. (2004). Pregnancy and perinatal outcomes of women with severe acute respiratory syndrome. Am. J. Obstet. Gynecol. 191, 292-297. 
Xie, X., Chen, J., Wang, X., Zhang, F., and Liu, Y. (2006). Age- and genderrelated difference of ACE2 expression in rat lung. Life Sci. 78, 2166-2171. doi: 10.1016/j.lfs.2005.09.038

Young, M. J., Clyne, C. D., and Chapman, K. E. (2020). Endocrine aspects of ACE2 regulation: Raas, steroid hormones and SARS-CoV-2. J. Endocrinol. 247, R45-R62.

Zou, X., Chen, K., Zou, J., Han, P., Hao, J., and Han, Z. (2020). Single-cell RNAseq data analysis on the receptor ACE2 expression reveals the potential risk of different human organs vulnerable to $2019-\mathrm{nCoV}$ infection. Front. Med. 14, 185-192. doi: 10.1007/s11684-020-0754-0
Conflict of Interest: The authors declare that the research was conducted in the absence of any commercial or financial relationships that could be construed as a potential conflict of interest.

Copyright $\odot 2021$ Wray and Arrowsmith. This is an open-access article distributed under the terms of the Creative Commons Attribution License (CC BY). The use, distribution or reproduction in other forums is permitted, provided the original author(s) and the copyright owner(s) are credited and that the original publication in this journal is cited, in accordance with accepted academic practice. No use, distribution or reproduction is permitted which does not comply with these terms. 